\title{
Research on the Employment Quality of College Graduates-Visual Analysis based on CNKI Literature Keywords
}

\author{
Si Jingwen \\ School of Education, Tianjin University, \\ Tianjin 300354, China \\ 2225344828@qq.com
}

\begin{abstract}
Under the background of the increasingly severe employment situation, the employment quality of college graduates has garnered a great deal of attention. In order to understand the status quo and trends of employment quality research, and to explore the hot spot of the present research on the quality of employment. This research is based on the current status of employment quality research, and uses high-frequency keyword frequency analysis and social network analysis methods to perform statistical analysis on the total of 587 keywords in 2000-2017 journal articles retrieved from the search. The results of the study show that clear definition of the main body of employment quality, specifically divided into employers, college graduates, colleges and labor market four objects; The analysis method is diversified, involving many subject areas, and the evaluation dimension gradually develops to a deeper level; Among the employment quality indicators, the three prominent hotspot indicators are employment ability, employment rate, and job satisfaction, the index covers a wide range of perspectives and highlights the hot spots of employment quality research.
\end{abstract}

Keywords-College graduates; Employment quality; Visualization; Research hotspot

\section{INTRODUCTION}

In 1999, for the first time, the Ministry of Education used the "employment rate" as an important indicator reflecting the dynamics of graduate employment, the employment rate has assumed an important historical mission of improving the employment awareness of colleges and universities, promoting breakthroughs in university reform and development, and optimizing professional structures and talent models. For a time, it has become a vane for the public to judge college rankings. With the diversification of graduates' employment and the continuous deepening of the employment system in universities, it is impossible to systematically, scientifically and comprehensively evaluate the quality, structure, level, and nature of employment in colleges and universities from the perspective of "quantity". And the importance of "quality" begins to appear. The concept of employment quality has promoted academic research in the establishment of systematic, scientific and all-round evaluation systems. Defining from the perspective of commodity science, the quality of employment is the sum of the characteristics of college graduates satisfying social needs on the premise of conforming to the basic laws of higher education [1]. Defining from the perspective of sociology, the quality of employment is the extent to which the quality of work that students can achieve and the inherent characteristics of their work meet their requirements [2]. Starting from full caliber, employment quality is measured by five dimensions: employment opportunities, employment incentives, employment environment, job satisfaction, and labor security [3]. This study believes that the employment quality is based on the employment market, combined with the employment expectations of employers, universities, society, and families, and the graduates' employment status under certain social conditions.

The study found that scholars defined the connotation of employment quality from the perspective of different disciplines, and the angle of employment quality measurement has certain characteristics of the times. Related hotspots have achieved initial results, but there are still deficiencies. This research uses the high-frequency keyword frequency analysis and social network analysis method, and uses BICOMB, UCINET to draw the co-occurrence matrix and visualized map of employment quality high-frequency keywords, presenting the status quo and hotspots of China's employment quality research from multiple angles. Identify key changes in the frequency of word frequency by analyzing the direction of changes in employment quality, and strive to find the frontier topics in this field in recent years, and provide suggestions and references for broadening research ideas.

\section{RESEARCH METHODS AND DATA PROCESSING}

\section{A. Research methods}

Word Frequency Analysis. The keywords are high generalization and refinement of the subject content of the paper. Although it occupies a small space, it is the core concept and key technology of the article. The research topic can be seen in the distribution of research themes. First of all, comb the article's keywords. Second, determine the closeness of two words based on the frequency of their appearance in the same article. This study uses high-frequency keywords in the journals of college graduates in the area of employment quality 
in order to find research hotspots and potential development directions in this field.

Social Network Analysis. The social network analysis method is a method of studying social networks and it explores deep-level structures. The types of identification of mutual relations can basically be represented by two research orientations: an overall network analysis, and a self-centered network analysis. This study uses the overall network analysis, first through the frequency analysis of words, and then combined with the central analysis, to clearly present the hot research on graduates' employment quality.

\section{B. Data Sources}

This study uses the CNKI database as a search statistic tool, and uses "employment quality" and "college graduates" as search terms. The search term is limited to "subject", the search time is 2000-2017, and the matching type is set. Set as "accurate" to retrieve 1,660 journal articles. On this basis, nonacademic articles with low relevance, such as reviews and interviews, were excluded, and 1,087 valid journal articles were finally identified. Key words in the literature were used as basic data for research.

\section{Data processing}

To study the hot issues of college graduates' employment quality, the main steps are as: First, the keywords of the searched valid documents are processed, the sample data is changed into a format recognizable by BICOMB, and highfrequency keywords in the area of employment quality are counted. Secondly, a co-occurrence matrix is constructed based on the relationship between high-frequency keywords. Finally, using Ucinet to draw the network visualization map, combined with the central analysis of employment quality research hotspots and development direction.

\section{ANALYSIS OF RESEARCH RESULTS}

\section{A. High-frequency keywords analysis}

This study combines the actual situation in the field of employment quality, and extracts keywords with a frequency threshold greater than 10, resulting in a total of 66 hot keywords (see Table 1 for details). In Table 1, the top ten keywords are: college graduates (435), universities (356), employment quality (267), employability (213), employment guidance (186), and analytic hierarchy process (156), employers (136), employment competitiveness (129), personnel training (125), employment rate (110). However, it is difficult to find the intrinsic logic based on the statistics of high-frequency keywords alone, and it is necessary to further explore the relationship between them through social network analysis.

TABLE I. HIGH FREQUENCY KEYWORDS STATISTICS

\begin{tabular}{|c|c|c|c|c|c|c|c|c|}
\hline No. & keywords & Frequency & No. & keywords & Frequency & No. & keywords & Frequency \\
\hline 1 & College graduates & 435 & 23 & Employment policy & 37 & 45 & Career orientation & 18 \\
\hline 2 & University & 356 & 24 & Employment status & 36 & 46 & $\begin{array}{c}\text { Professional- counterpart } \\
\text { rate }\end{array}$ & 18 \\
\hline 3 & Employment- quality & 267 & 25 & practical teaching & 36 & 47 & $\begin{array}{l}\text { One-time- employment } \\
\text { rate }\end{array}$ & 18 \\
\hline 4 & Employability & 213 & 26 & Employment pressure- & 36 & 48 & quality of education & 18 \\
\hline 5 & Career Guidance & 186 & 27 & Employment satisfaction & 33 & 49 & Comprehensive- quality & 17 \\
\hline 6 & $\begin{array}{c}\text { Analytic Hierarchy- } \\
\text { Process }\end{array}$ & 156 & 28 & Teaching Quality & 33 & 50 & Gender difference & 17 \\
\hline 7 & Employers & 136 & 29 & factor analysis & 29 & 51 & $\begin{array}{l}\text { Principal- component } \\
\text { analysis }\end{array}$ & 16 \\
\hline 8 & $\begin{array}{l}\text { Employment-- } \\
\text { competitiveness }\end{array}$ & 129 & 30 & Professional settings & 27 & 52 & Employment--concept & 16 \\
\hline 9 & talent development & 125 & 31 & Initial employment- rate & 26 & 53 & Teaching mode & 16 \\
\hline 10 & employment rate & 110 & 32 & Vocational education & 25 & 54 & Social capital & 16 \\
\hline 11 & $\begin{array}{l}\text { Entrepreneurship- } \\
\text { Education }\end{array}$ & 84 & 33 & Cluster analysis & 24 & 55 & Third-party- evaluation & 15 \\
\hline 12 & labour market & 52 & 34 & Employment psychology & 24 & 56 & Core- competitiveness & 13 \\
\hline 13 & career plan & 51 & 35 & Professionalism & 23 & 57 & $\begin{array}{l}\text { Structural equation- } \\
\text { model }\end{array}$ & 12 \\
\hline 14 & Teaching Reform- & 49 & 36 & The employment- situation & 23 & 58 & career planning & 12 \\
\hline 15 & $\begin{array}{l}\text { Fuzzy comprehensive-- } \\
\text { evaluation method }\end{array}$ & 45 & 37 & Three-party- satisfaction & 21 & 59 & Self-evaluation & 12 \\
\hline 16 & Career guidance & 43 & 38 & Social needs & 21 & 60 & Instructional design & 11 \\
\hline 17 & Curriculum & 42 & 39 & human capital & 20 & 61 & Career Development & 11 \\
\hline 18 & Empirical Research & 41 & 40 & Mental health & 20 & 62 & SWOT analysis & 10 \\
\hline 19 & Career choice & 41 & 41 & Course construction & 19 & 63 & Job Satisfaction & 10 \\
\hline 20 & Questionnaire & 39 & 42 & Entrepreneurial ability & 19 & 64 & Pay level & 10 \\
\hline 21 & Employment- concept & 39 & 43 & curriculum structure & 19 & 65 & Course reform & 10 \\
\hline 22 & Job evaluation & 38 & 44 & compare research & 18 & 66 & $\begin{array}{l}\text { Innovation and- } \\
\text { entrepreneurship }\end{array}$ & 10 \\
\hline
\end{tabular}




\section{B. Social Network Analysis}

Construct a co-occurrence matrix based on high-frequency keywords tables to further tap the relationship between highfrequency keywords. When two keywords appear at the same time in an article, there is a certain correlation between the two.
For example, the second and third columns in the matrix have a focus value of 3 , that is, college graduates and colleges appear three times in the same article. The diagonal values represent the frequency of occurrence of the keywords (see Table 2 for details).

TABLE II. HIGH-FREQUENCY KEYWORDS CO-OCCURRENCE MATRIX (PART)

\begin{tabular}{cccccc}
\hline & College graduates & University & Employment quality & Employability & Career Guidance \\
\hline College graduates & 435 & 3 & 1 & 2 & 0 \\
University & 3 & 356 & 0 & 0 & 1 \\
Employment quality & 1 & 0 & 267 & 213 & 12 \\
Employability & 2 & 0 & 1 & 12 & 186 \\
Career Guidance & 0 & 0 & 3 &
\end{tabular}

1) Visualization analysis

The social network analysis structure of high-frequency keywords of college graduates' employment quality is shown in Figure 1. It can be seen that: First, keywords such as college graduates, employability, employment competitiveness, and employment guidance are not only at the center of the social network graph, but also have high frequency, indicating that these keywords are currently the research hotspots in the area of employment quality. Second, keywords such as vocational education, comprehensive quality, entrepreneurial ability, and teaching reform are at the edge of the Internet, meaning that these keywords may become potential hot spots in the field of China's employment quality research. Thirdly, the evaluation indicators such as factor analysis, analytic hierarchy process, empirical research, and cluster analysis are on one side of the network, indicating that the combination of evaluation methods and indicators has yet to be improved. The adoption of scientific evaluation methods is the research and development direction in the area of employment quality.

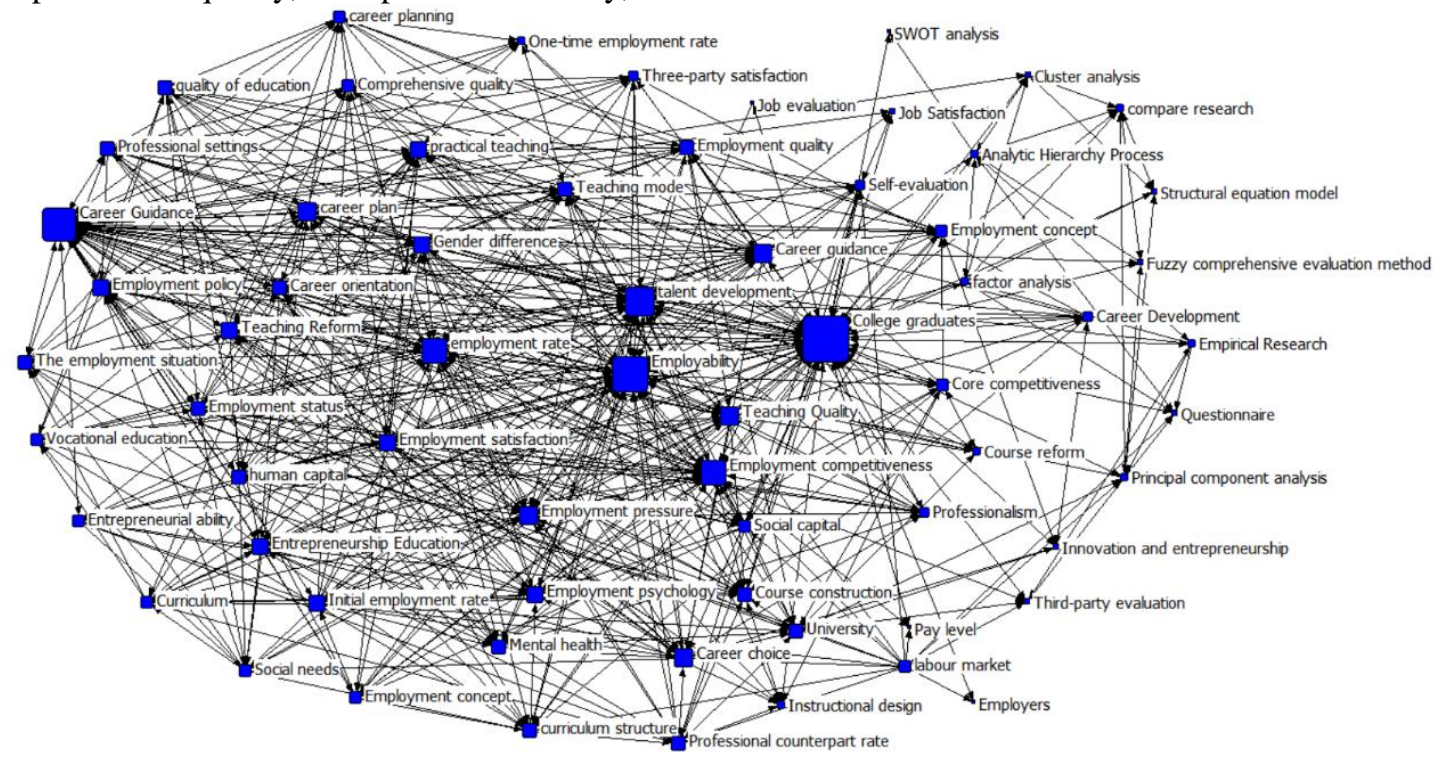

Fig. 1. Visualization of high-frequency keywords

\section{2) Social Network Density Analysis}

Social network density represents the degree of closeness between the nodes of the entire network. The closer the density value is to 1 , the closer the key is. The social network density of high-frequency keywords in this field is 0.5982, indicating that the relationship between high-frequency keywords is relatively close, that is to say, there is a close connection between the fields of employment quality research.

\section{3) Keywords analysis}

In a social network, if there is a direct connection between an actor and many other actors, then the actor is in the center of the social network and has a large "power" in the network [4]. The purpose of the central analysis of the employment quality of college graduates is to understand the position of each index in the entire network, so as to further explore the employment quality of college graduates. From Table 2, it can be seen that the keywords of college graduates and employability are more central in point, indicating that the research on college graduates' employability is the current focus. Talent cultivation 
and employment competitiveness follow closely, indicating that this keyword plays a role as a bridge in the social network analysis map and is the direction of future research.

TABLE III. CENTRALIZED ANALYSIS OF HIGH FREQUENCY KEYWORDS (PART)

\begin{tabular}{|c|c|c|}
\hline No. & keywords & Point Centrality \\
\hline 1 & College graduates & 696 \\
\hline 2 & Employability & 300 \\
\hline 3 & labour market & 288 \\
\hline 4 & Career Guidance & 218 \\
\hline 5 & talent development & 195 \\
\hline 6 & Employment competitiveness & 144 \\
\hline$\ldots \ldots$ & $\ldots \ldots$ & $\ldots \ldots$ \\
\hline 66 & SWOT analysis & 7 \\
\hline
\end{tabular}

\section{Research hotspot analysis}

According to the characteristics of high-frequency keywords and the analysis of centrality, the indicators in the network are classified, and many research features in the field of college graduates' employment quality are specifically understood. This study divides high-frequency keywords into three categories: employment quality research, employment quality research, and employment quality index research.

\section{Body}

1) Research Hotspot One: Employment Quality Main

These include the keywords: college graduates, colleges, employers and the labor market. The research hotspot shows that the research on the employment quality of college graduates cannot be separated from the participation of universities, employers and the labor market. For college graduates, high-quality employment is the need to improve self-development and enhance their own value. For colleges and universities, the employment quality of graduates is related to the important links of personnel training for colleges and universities, such as enrollment plans, professional settings, and employment guidance. For employers, the employment quality of graduates is the standard for the selection of talents for enterprises. For the labor market, the quality of employment plays a crucial role in the level of economic development.

\section{2) Research Hotspot Two: Employment Quality Method}

These include keywords: AHP, fuzzy comprehensive evaluation, empirical research, questionnaire survey, factor analysis, cluster analysis, comparative research, principal component analysis, third-party evaluation, structural equation model, and SWOT analysis. The research hotspots show that the types of evaluation methods are diverse, involving many disciplines such as statistics, sociology, and management. There are many qualitative analysis methods in the evaluation methods, but few quantitative analysis applications. In the future, the selection of research methods should use a combination of quantitative and qualitative methods, such as the combination of analytic hierarchy process and expert evaluation methods. The results obtained by using scientific evaluation methods are more comprehensive and objective, and the greater the contribution value to the study of employment quality.

\section{3) Research Hotspot Three: Employment Quality} Indicators

These include 51 key words: employment quality, employability, employment guidance, employment competitiveness, personnel training and employment rate etc. The three prominent hotspot indicators are the employment ability index, employment rate index and employment satisfaction index.

\section{a) Employability indicators}

Taking employment ability as a representative indicator, related indicators include employment competitiveness, entrepreneurial ability, core competitiveness, and overall quality. The level of employability is a direct manifestation of the level of teaching quality in colleges and universities. Some scholars have proposed that the graduates' employment ability is divided into six factors: knowledge skills, self-management skills, competency, leadership, career planning and social adaptability [5]. Explaining that the current labor market requires high graduates' employability. Therefore, when cultivating talents, colleges and universities should focus on cultivating graduates' comprehensive capabilities to achieve market-oriented employment requirements. Graduates should pay attention to the development of comprehensive abilities to meet the needs of the talent market in their personal development.

\section{b) Employment rate indicator}

The employment rate is a representative index, and related indicators include the initial employment rate and one-time employment rate. For a long time, the employment rate of college graduates in China actually refers to the one-time employment rate or the initial employment rate. However, as scholars study the employment rate in depth, in order to overcome the intension of the indicators, secondary employment rate and year-end employment rate are added to 
measure employment rate. In recent years, with the adjustment of national policies, self-employment rates and other self-report indicators reflecting the employment rate of graduates have emerged. Through self-employment, not only graduates can solve employment problems but also create more employment opportunities for the society, that is encouraging employment through entrepreneurship. On the whole, the hot research on the employment rate is still focused on "quantity" and "quality". It is not just to look at the "rate", but to look at the essence through the phenomenon. The employment rate should reflect the ability of the people trained in colleges and universities. To serve the market economy, whether the state's investment in higher education can be fully implemented, whether the talent standards required by employers can be consistent with the training results of universities, and whether graduates' expected jobs can match the opportunities provided by the labor market.

\section{c) Job satisfaction indicators}

Employment satisfaction is the representative indicator, and relevant indicators include tripartite satisfaction and job satisfaction. From the indicators of satisfaction, we can see that scholars currently measure the employment quality of college graduates mainly from the perspectives of the labor market, college graduates, employers and universities. Among them, employers need to consider the optimization of labor costs, and the graduates' working ability will affect the satisfaction of employers. Employment satisfaction is the core index, no matter from which perspective, the standard of employment quality of college graduates changes with the development of the social economy. No matter which party is the subject, it should follow the footsteps of social development to improve the quality of employment.

\section{CONCLUSION AND OUTLOOK}

This research uses high-frequency keywords frequency analysis and social network analysis method to sum up the hot spots and frontiers in the field of employment quality of college graduates in China. The disadvantage is that only the key words are analyzed and thought. In order to understand the hot spots and development trends of employment quality, it should combine the relevant research results from abroad and take the road of developing the quality of employment in line with Chinese characteristics. The future career guidance and employment quality, innovation and entrepreneurship and employment quality should be focused. First, career guidance plays a key role in the employment of graduates. In particular, the vocational guidance of vocational colleges, the guiding and career counseling of the students' vocational values are the major difficulties in vocational guidance. The quality of employment cannot be separated from the training of the school. The current career guidance in our country is in the development stage. One of the future development trends is the study of vocational guidance, such as the professionalization of the professional guidance system, the professionalization of professional guidance, the maturity of the career guidance system, and the standardization of relevant laws and regulations. Second, employment quality is combined with innovation and entrepreneurship. The output of development education is employment. With the development of a fair and quality education in the country, everyone has the opportunity to change their own destiny through education, then achieve full employment at a certain level. In the context of the "Internet+" era, the Internet and other informatization methods are used to strengthen education and social progress. Starting from the needs of economic and social development, the "Internet + " innovation model will be adopted to optimize the structure of higher education. Employers should improve the consultation mechanism of labor relations, eliminate discrimination on the basis of sex and status, making more equitable and full employment become the highlight of China's development.

\section{REFERENCES}

[1] Ke Yu. Construction of Evaluation Index System for Employment Quality of College Graduates [J]. China Higher Education Research, 2007, (07): 82-85.(In Chinese)

[2] Song Lizhen. Thoughts on the evaluation system of college graduates' employment quality [J]. Heilongjiang Higher Education Research, 2016, (05): 118-121. (In Chinese)

[3] Zhang Kangshen, Liu Cuihua, Yan Youshan. Employment Quality of University Graduates: Full-caliber Index Evaluation and Empirical Test [J]. Economics and Management Research, 2015, (09): 60-66. (In Chinese)

[4] John Scott. Social Network Analysis Methods (2nd Edition) [M] Liu Jun Chongqing: Chongqing University Press, 2009. (In Chinese)

[5] Ma Yongxia, Liang Jinhui. Research on the Evaluation of University Students' Employment Ability[J]. Educational Research 2016, (09): 4050. (In Chinese)

[6] Zhang Yaoxiang. Research on Evaluation of Employment Quality of College Graduates Based on Three-Party Satisfaction[J]. China Higher Education Research, 2013, (05): 82-86. (In Chinese) 